\title{
Korelasi Luaran dengan Ketebalan dan Lokasi Perdarahan Subaraknoid pada Pasien Cedera Kepala di RSUD Arifin Achmad
}

\author{
Andrea Valentino*
}

\begin{abstract}
Subarachnoid hemorrhage (SAH)in head injury is a very common case. Research showed that $33 \%$ moderate and severe head injury patients had SAH during initial $C T$ scan. A prospective study was performed on 37 head injury patients with SAH which had been treated in Arifin Achmad Hospital during January to June 2014 period. Bivariable analysis that was used in this research was an unpaired categorical analytic statistical test, the chi square test. Meanwhile, multivariable analysis used was multiple logistic regression test. Significance was determined based on $p$ value, which was d"0.05, and confidence interval (CI) of 95\%. There were unfavourable outcome upon head injury patients with SAH of $>5 \mathrm{~mm}$ thickness $(\mathrm{p}=0,028)$ and located at cerebral hemisphere and basal cistern $(\mathrm{p}=0,001)$. Thickness and SAH location was found to be associated with head injury patient outcome. SAH thickness of $>5 \mathrm{~mm}$ against outcome had a stronger association than location as a factor.
\end{abstract}

Keywords: head injury, outcome, subarachnoid hemorrhage thickness, subarachnoid hemorrhage location

Cedera kepala merupakan kasus yang masih menjadi penyebab mayoritas dari kematian dan kecacatan pada usia muda dimana terjadi lebih dari $2 \%$ dari populasi dunia. ${ }^{1}$ Penderita cedera kepala yang cukup berat di Amerika yang dirawat di rumah sakit kurang lebih 100 sampai 400 per 100000 orang. ${ }^{2}$ Angka kejadian cedera kepala di Indonesia belum didapatkan data resmi, di RSUD Dr. Soetomo Surabaya didapatkan data penderita cedera kepala pada tahun 2006 terdapat 1588 pasien dengan total kematian $6,171 \%$. $^{3}$

Perdarahan subaraknoid adalah suatu keadaaan terdapatnya darah dalam rongga subaraknoid yang menyelimuti otak dan medula spinalis. Dalam keadaan normal rongga ini terisi oleh cairan serebrospinal yang jernih dan tidak berwarna, pembuluh darah serta jaringan penunjang berbentuk trabekula halus. ${ }^{4}$

Perdarahan subaraknoid pada cedera kepala adalah kasus yang sering terjadi. ${ }^{5}$ Sebelum era $C T$

\footnotetext{
* Correspondence address : dr reano@yahoo.com, Division of Neurosurgery-Departement of Surgery, Faculty of Medicine, Riau University, Jalan Diponegoro No.1 Pekanbaru
}

scan, diagnosis ditegakkan dengan otopsi. Perdarahan subaraknoid akibat cedera merupakan lesi yang paling sering ditemukan dan berhubungan dengan terjadinya lesi yang lain seperti kontusi dan perdarahan subdural. ${ }^{6-8}$ Angka kejadian dari perdarahan subaraknoid pada cedera kepala masih belum pasti, tetapi dari literatur menyebutkan 25$30 \%$ pada cedera kepala sedang dan berat. ${ }^{8}$ Pada penelitian yang dilakukan di Eropa, menunjukkan bahwa $33 \%$ penderita cedera kepala sedang dan berat didapatkan gambaran perdarahan subaraknoid pada pemeriksaan awal CTscan, dan pada pasien ini secara signifikan menunjukkan luaran yang buruk dibandingkan dengan yang tidak didapatkan gambaran perdarahan subaraknoid. ${ }^{9,10}$

Faktor yang menghubungkan perdarahan subaraknoid dengan luaran yang spesifik pada pasien cedera kepala belum sepenuhnya diketahui. Terdapat dua hipotesis yang telah dilaporkan adalah bahwa perdarahan subaraknoid pada cedera merupakan indikator beratnya kerusakan jaringan otak akibat cedera dan perdarahan subaraknoid berhubungan dengan mekanisme kerusakan beruntun seperti terjadinya vasospasme dan iskemia. Kebanyakan penelitian yang dilaporkan berhubungan dengan ada atau tidaknya perdarahan 
subaraknoid untuk menentukan luaran hanya berdasarkan $C T$ scan pada saat pertama kali datang ke rumah sakit. ${ }^{11}$

Diagnosis perdarahan subaraknoid mudah ditegakkan dengan adanya rekonstruksi $C T$ scan untuk melihat potongan sagital ataupun coronal. ${ }^{12}$ Beberapa penelitian memfokuskan dalam menjelaskan pola perdarahan subaraknoid akibat cedera sesuai dengan gambaran pada $C T$ scan, dan prognosis sesuai dengan pola tersebut. ${ }^{13-15}$ Salah satu laporan sebelumnya menyatakan adanya hubungan yang penting antara ketebalan dari perdarahan subaraknoid traumatika. ${ }^{16}$

\section{METODE}

Kriteria inklusi penelitian adalah semua pasien cedera kepala yang dilakukan $C T$ scan kepala di RSUD Arifin Achmad serta didiagnosis sebagai perdarahan subaraknoid dan dirawat di bangsal bedah selama periode Januari hingga Juni 2014. Kriteria eksklusi penelitian adalah pasien cedera kepala dengan trauma multipel dan luka penetrans.

Jenis penelitian yang digunakan merupakan penelitian cross sectional yang bertujuan mencari hubungan antara dua variabel atau lebih dengan metode pengumpulan data secara prospektif. Variabel bebas pada penelitian ini adalah tebal perdarahan subaraknoid dan lokasi perdarahan subarakhnoid akibat cedera kepala. Variabel tergantung pada penelitian ini adalah outcome pada pasien cedera kepala yang dinilai dengan Glascow Outcome Scale (GOS).

Data dikumpulkan berdasarkan cara consecutive sampling, yaitu subjek penelitian diambil pada waktu pertama kali didiagnosis di Instalasi Gawat Darurat RSUD Arifin Achmad hingga tercapainya jumlah sampel. Besar sampel ditentukan berdasarkan formula uji hipotesis dua proporsi dan didapatkan total besar sampel minimal 36 orang.

Analisis data disesuaikan dengan tujuan dan hipotesis penelitian, dengan menggunakan program komputer. Analisis bivariabel pada penelitian ini digunakan uji statistik analitik kategorikal tidak berpasangan yaitu dengan menggunakan Chi Square Test. Analisis mutivariabel yang digunakan untuk menguji faktor yang paling dominan (ketebalan dan lokasi perdarahan subaraknoid) berhubungan dengan outcome pada pasien cedera kepala menggunakan Multiple Logistic Regression Test. Kemaknaan ditentukan berdasarkan nilai p, yaitu d" 0,05 dan confidence interval (CI) sebesar $95 \%$.

\section{HASIL}

Tabel 1. Karakteristik subjek penelitian berdasarkan usia, jenis kelamin dan GCS pasien trauma kepala

\begin{tabular}{lcccccc}
\hline \multicolumn{1}{c}{ Variabel } & Rerata & SD & Median & Rentang & n & \% \\
\hline Umur (tahun) & 38,30 & 18,58 & 32,00 & $15-72$ & & \\
Jenis Kelamin & & & & & 29 & 78,4 \\
$\bullet \quad$ Laki-laki & & & & & 8 & 21,6 \\
$\bullet \quad$ Perempuan & & & & & \\
GCS Masuk RS & 9,49 & 3,19 & 10,00 & $4-15$ & & \\
GCS Keluar RS & 9,30 & 6,49 & 12,00 & $3-15$ & & \\
\hline
\end{tabular}

Tabel 2. Karakteristik subjek penelitian berdasarkan ketebalan dan lokasi perdarahan subaraknoid pasien trauma kepala

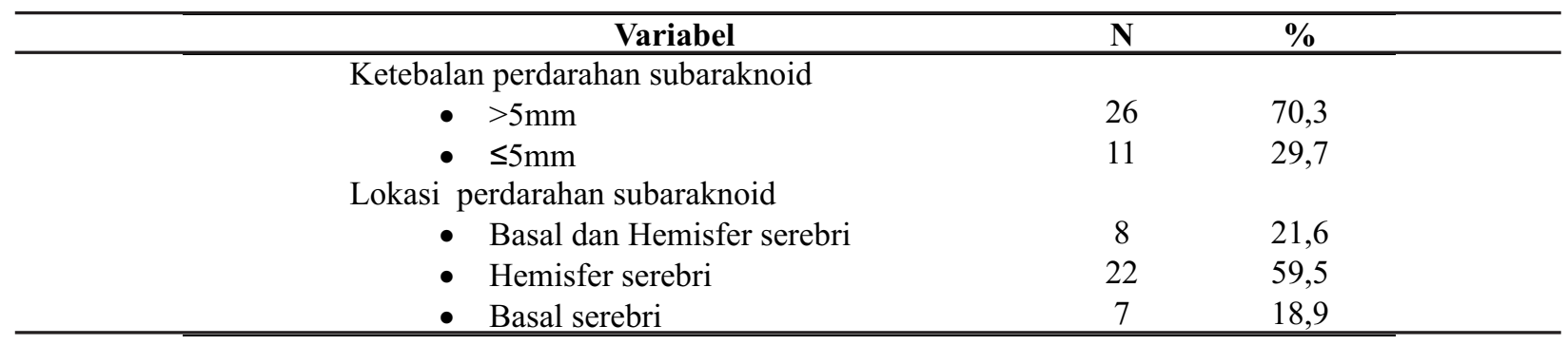


Tabel 3. Karakteristik subjek penelitian berdasarkan GOS keluar RS dan luaran pasien trauma kepala

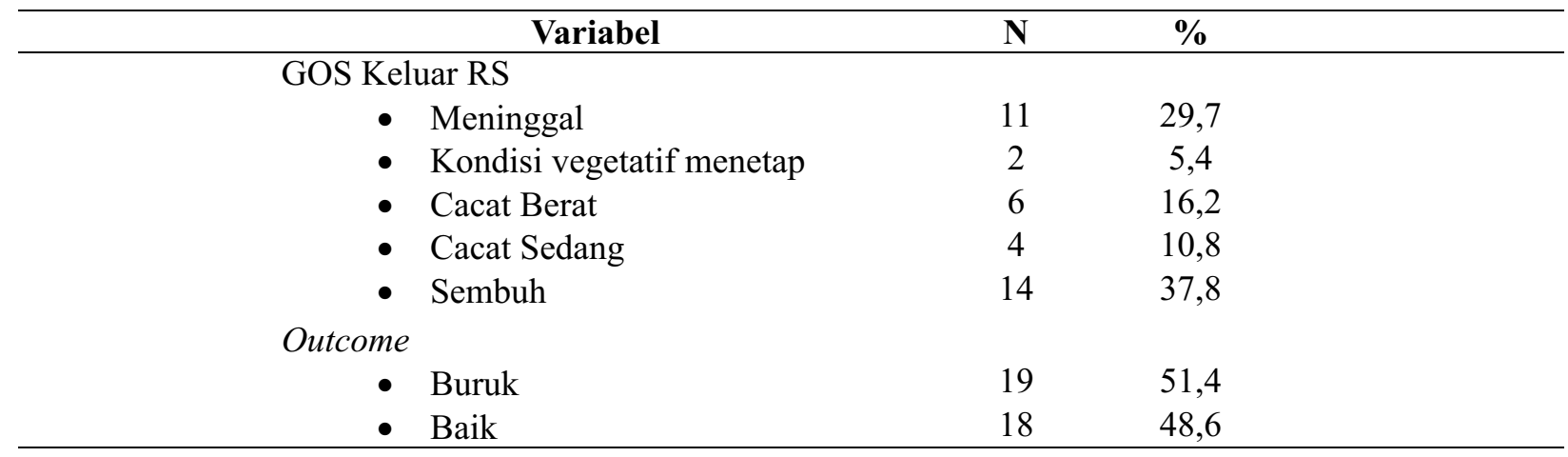

Tabel 4. Hubungan antara ketebalan perdarahan subaraknoid dengan luaran pasien trauma kepala

\begin{tabular}{|c|c|c|c|c|c|}
\hline \multirow[t]{3}{*}{ Variabel } & \multicolumn{4}{|c|}{ Outcome } & \multirow[t]{3}{*}{ Nilai $p$} \\
\hline & \multicolumn{2}{|c|}{ Jelek } & \multicolumn{2}{|c|}{ Baik } & \\
\hline & $\mathrm{n}$ & $\%$ & n & $\%$ & \\
\hline $\begin{array}{l}\text { Ketebalan perdarahan } \\
\text { subaraknoid }\end{array}$ & & & & & 0,028 \\
\hline - $>5 \mathrm{~mm}$ & 16 & 84,2 & 10 & 55,6 & \\
\hline - $\quad<5 \mathrm{~mm}$ & 3 & 15,8 & 8 & 44,4 & \\
\hline
\end{tabular}

Tabel 5. Hubungan antara lokasi perdarahan subaraknoid dengan luaran pasien trauma kepala

\begin{tabular}{|c|c|c|c|c|c|}
\hline \multirow[t]{3}{*}{ Variabel } & \multicolumn{4}{|c|}{ Luaran } & \multirow[t]{3}{*}{ Nilai $p$} \\
\hline & \multicolumn{2}{|c|}{ Jelek } & \multicolumn{2}{|c|}{ Baik } & \\
\hline & $\mathbf{n}$ & $\%$ & $\mathbf{n}$ & $\%$ & \\
\hline $\begin{array}{c}\text { Lokasi perdarahan subaraknoid } \\
\text { - Basal dan Hemisfer } \\
\text { serebri }\end{array}$ & 7 & 36,8 & 0 & 0,0 & 0,001 \\
\hline - Hemisfer serebri & 8 & 42,1 & 14 & 77,8 & \\
\hline - Basal serebri & 4 & 21,1 & 4 & 22,2 & \\
\hline
\end{tabular}

Tabel 6. Analisis hubungan yang paling dominan antara ketebalan dan lokasi perdarahan subaraknoid dengan luaran pasien trauma kepala

\begin{tabular}{|c|c|c|c|c|c|c|}
\hline Model & $\begin{array}{c}\text { Variabel } \\
\text { Dependent }\end{array}$ & $\begin{array}{c}\text { Variabel } \\
\text { Independent }\end{array}$ & $\begin{array}{c}\text { Koefisen } \\
\beta \\
\end{array}$ & SE & $\begin{array}{c}\text { Nilai } \\
p\end{array}$ & OR $(95 \% \mathrm{CI})$ \\
\hline \multirow[t]{3}{*}{ Awal } & Luaran & & & & & \\
\hline & & $\begin{array}{l}\text { - Ketebalan } \\
\text { perdarahan }\end{array}$ & 1,507 & 0,782 & 0,054 & $\begin{array}{l}4,51(0,97- \\
20,89)\end{array}$ \\
\hline & & $\begin{array}{ll}\text { - } & \text { lokasi } \\
\text { perdarahan } \\
\text { subaraknoid } \\
\text { - Konstanta }\end{array}$ & $\begin{array}{l}0,187 \\
-2,675\end{array}$ & 0,592 & 0,752 & $\begin{array}{c}1,21(0,37- \\
3,84)\end{array}$ \\
\hline \multirow[t]{2}{*}{ Akhir } & Luaran & & & & & \\
\hline & & $\begin{array}{l}\text { - Ketebalan } \\
\text { perdarahan } \\
\text { subaraknoid } \\
\text { - Konstanta }\end{array}$ & $\begin{array}{l}1,558 \\
-2,557\end{array}$ & 0,767 & 0,042 & $\begin{array}{c}4,75(1,05- \\
21,36)\end{array}$ \\
\hline
\end{tabular}




\section{PEMBAHASAN}

Subyek pada penelitian ini adalah 37 orang, sebagian besar subjek penelitian adalah laki-laki sebanyak 29 orang $(78,4 \%)$, median usia 32 tahun, yang merupakan usia produktif, dengan median GCS masuk RS adalah 10 dengan GCS masuk RS paling rendah 4 dan GCS masuk RS paling tinggi adalah 15. Hal ini disebabkan karena mobilitas laki-laki usia produktif dengan menggunakan kendaran bermotor yang tinggi. ${ }^{17}$

Data penelitian menunjukkan bahwa sebagian besar subjek penelitian dengan ketebalan perdarahan subaraknoid $>5 \mathrm{~mm}$ sebanyak 26 orang $(70,3 \%)$ dan lokasi perdarahan subaraknoid adalah hemisfer cerebri sebanyak 22 orang $(59,5 \%)$. Hal ini sesuai dengan hasil penelitian lain yang juga menyebutkan bahwa terjadinya perdarahan subaraknoid traumatik paling banyak didapatkan pada hemisfer serebri, karena hemisfer mempunyai permukaan yang paling luas, dan yang paling sering menerima benturan pada waktu terjadinya trauma. ${ }^{18}$ Perdarahan pada lobus parieto-oksipital berasal dari vena cerebri superior yang masuk ke dalam sinus sagitalis superior akibat perubahan posisi relatif antara otak dengan tulang tengkorak. ${ }^{19}$ Perdarahan subaraknoid pada Fissura Sylvii mungkin terjadi akibat adanya kontusi pada lobus temporal. ${ }^{20}$

Berdasarkan uji statistik menggunakan uji Chi Square pada derajat kepercayaan $95 \%$ dengan nilai $\mathrm{p}<0,05$, penelitian ini menunjukkan bahwa terdapat hubungan secara bermakna antara ketebalan perdarahan subaraknoid dengan luaran pasien trauma kepala. Penelitian lain yang memfokuskan dalam menjelaskan pola perdarahan subaraknoid akibat trauma sesuai dengan gambaran pada CT scan, dan prognosis sesuai dengan pola tersebut menunjukkan adanya hubungan yang penting dengan luaran. ${ }^{21,22}$

Semakin tebal perdarahan subaraknoid yang didapatkan pada CT scan semakin banyak volume darah yang terdapat pada ruang subaraknoid. Berdasarkan hipotesis sebelumnya, bahwa produk perombakan darah yang berupa oksihemoglobin akan lebih banyak dihasilkan yang selanjutnya akan menginisiasi terjadinya hipertrofi, fibrosis dan degenerasi serta perubahan inflamatorik lain pada dinding pembuluh darah yang akan menyebabkan kontraksi otot polos yang berkepanjangan menyebabkan terjadinya vasospasme arterial. ${ }^{23}$

Perdarahan subaraknoid traumatik juga dikatakan sebagai penanda adanya kekuatan mekanik yang besar daripada sebagai sebuah indikator luaranyang jelek pada pasien trauma kepala. $^{24}$

Pada tabel 5 menunjukkan subjek penelitian dengan lokasi perdarahan subaraknoid pada basal dan hemisfer serebri memiliki luaranjelek lebih besar, yaitu 36,8 \%, sedangkan tidak ditemukan subjek dengan luaran baik. Perdarahan subaraknoid seperti ini disebut sebagai perdarahan subaraknoid generalisata. Perdarahan subaraknoid ini dikatakan terjadi akibat ruptur arteri dan kontusio serebri yang hebat, ${ }^{25}$ dan secara statistik terdapat hubungan secara bermakna antara lokasi perdarahan subaraknoid dengan luaran pasien trauma kepala dengan nilai $\mathrm{p}=0,001$.

Subjek yang mengalami perdarahan pada sisterna basal semuanya menunjukkan luaran baik, hal ini sesuai dengan data otopsi yang dilakukan Freytag (1963) yang menyatakan perdarahan pada sisterna basal tanpa adanya kerusakan otak yang lain akibat trauma. Sumber perdarahan biasanya tidak terlihat, trauma kepala biasanya hanya ringan, dan berhubungan dengan intoksikasi alkohol. ${ }^{25}$ Data dari penelitian ini menunjukkan semakin luas area yang didapatkan gambaran perdarahan subaraknoid berarti semakin banyak volume darah yang terdapat di ruang subaraknoid, yang mengakibatkan semakin buruk luarannya. ${ }^{16}$

Hasil uji Multiple Logistic Regression menunjukkan bahwa ketebalan perdarahan subaraknoid berhubungan paling dominan dengan luaran pasien trauma kepala dengan koefisen beta sebesar 1,558 dengan OR 4,75 (1,05-21,36) yang menunjukkan bila ketebalan perdarahan subaraknoid $>5 \mathrm{~mm}$ maka memiliki risiko GOS yang buruk 4,75 kali lebih besar dibandingkan ketebalan perdarahan subaraknoid d"5 $\mathrm{mm}$ dengan nilai $\mathrm{p}=0,042$.

Kendala dari penelitian ini dalam diagnosis adalah adanya artefak yang terjadi akibat pergeseran pada waktu dilakukan CT scan, rendahnya kadar hemoglobin dalam ruang subaraknoid yang dengan cepat teridstribusi, dan posisi kepala pada waktu 
proses CT scan serta keterbatasan dalam meminimalkan faktor risiko lain yang dapat mempengaruhi luaran pasien trauma kepala, karena banyak sekali faktor-faktor lain yang dapat mempengaruhi luaran pada pasien trauma kepala dan tidak dilakukan penilaian secara radiologis yang dapat membuktikan adanya vasospasme serebri ataupun infark serebri. Namun dengan adanya datadata penelitian yang sudah dipaparkan, diharapkan dapat menjadi dasar untuk penelitian selanjutnya.

\section{KESIMPULAN}

Perdarahan subaraknoid pada pasien trauma dengan $C T$ scan menunjukkan ketebalan $>5 \mathrm{~mm}$ merupakan faktor prognostik negatif terhadap luaran pasien trauma kepala. Lokasi perdarahan subaraknoid pada sisterna basal dan hemisfer serebri menunjukkan luaran yang buruk.

\section{DAFTAR PUSTAKA}

1. LiauL M, Bergsneider M, Becker DP; Pathology and pathophysiology of head injury, Youmans Neurological Surgery Fourth Edition.18810

2. Narayan R K, Suzanne K. Closed head injury in principles of neurosurgery. Elsevier Mossby, Edinburgh 2005. p. 300 - 304.

3. Tim Neurotrauma, Pedoman tatalaksana cedera otak, RSU Dr. Soetomo, FK Universitas Airlangga, Surabaya 2007.

4. Robert HR ; Mild traumatic brain injury ; J. Neurosurgery, 1997;87:234-8.

5. Mattioli C. Traumatic subarachnoid hemorrhage on the computerized tomography scan obtained at admission: a multicenter assessment of the accuracy of diagnosis and the potential impact on patient outcome. J Neurosurg 2003; 98:3742.

6. Paiva WS. De Andrade AF. De Amorim RL. Muniz PK, Bernardo LS, Figueiredo EG, Teixeir $\mathrm{MJ}$ : The prognosis of the TSAH : A prospective repot of 121 patients Int. Surg 2010;95:172-6.

7. Freytag E: Autopsy findings in head injuries from blunt forces. Statistical evaluation of 1,367 cases. Arch Pathol 1963; 75:402-413.
8. Gaetani P, Tancioni F, Tartara F, et al: Prognostic value of the amount of post-traumatic subarachnoid haemorrhage in a six month follow up period. J Neurol Neurosurg Psychiatry 1995; 59: 635-637.

9. Choi JH, Jakob M, Stapf C, Marshall RS, Hartmann A, Mast H: Multimodal early rehabilitation and predictors of outcome in survivors of severe traumatic brain injury. J Trauma 65; 2008:1028-1035.

10.Compagnone C, d'Avella D, Servadei F, Angileri FF, Brambilla G, Conti C, et al: Patients with moderate head injury: a prospective multicenter study of 315 patients. Neurosurgery 2009; 64:690-697.

11. Chieregato A, Fainardi E, Morselli-Labate, AM, et al ; Factors associated with neurological outcome and lesion progression in traumatic subarachnoid hemorrhage patients, Neurosurgery, April 2005; 56:4:671-681

12.Zacharia TT, Nguyen DT: Subtle pathology detection with multidetector row coronal and sagittal CT reformations in acute head trauma. Emerg Radiol 2010; 17:97-102.

13. Chieregato A, Fainardi E, Morselli-Labate AM, Antonelli V, Compagnone C, Targa L, et al: Factors associated with neurological outcome and lesion progression in traumatic subarachnoid hemorrhage patients. Neurosurgery 2005; 56:671-680.

14.Miki T, Ikeda Y, Utsugi O, Ito H: Evaluation of traumatic subarachnoid haemorrhage on computed tomography. J Clin Neurosci 5:49-57, 1998

15.Morris GF, Marshall LF: A new practical classification of traumatic subarachnoid hemorrhage. Clin Neurol Neurosurg 1997.; 99 (1):S16.

16.Greene KA, Jacobowitz R, Marciano FF, Johnson BA, Spetzler RF, Harrington TR: Impact of traumatic subarachnoid hemorrhage on outcome in nonpenetrating head injury. PartI: Relationship to clinical course and outcome variables during acute hospitalization. J Trauma 1996; 41:964-971. 
17.George KC Wong, Janice HH Yeung, Colin A Graham : Neurological outcome in patients with traumatic brain injury and its relationship with computed tomography pattern of subarachnoid hemorrhage. J Neurosurge 2011; 114 : 15101515.

18.Peter L Reilly, Ross Bullock : Head injury pathophysiology and management second edition , Hodder Arnold, Great Britain, 2005.

19.Ben Selladurai, Peter L Reilly : Initial management of head injury a comprehensive guide, McGraw-Hill, Sydney, 2007.

20.Jennet B, Macmillan R : Epidemiology of head injury, Arch Dis Child 1998;78:403-6

21.Jennet B, Teasdale GM : Assessment of coma and impaired consciousness : a practical scale, Lancet 1974;81- 4
22.Raj K Narayan, Suzanne Kempisty ; Closed head injury in principles of neurosurgery Second edition , Elsevier Mosby, Philadelphia, 2005, hal:302 - 317

23.G Teasdale, P Mathew ; Mechanismsof cerebral concussion, contusion, and other effects of head injury in Youmans Neurological Surgery; 4/e, ebook edition

24.Gennarelli, T A ; Mechanisms of brain injury. J Emerg Med 1993;11:5.

25.Gennarelli, T A, Spielman G M, Langfit T W, et al : Influence of the type of intracranial lesion on the outcome from severe head injury, $\mathrm{J}$ Neurosur 1982;56:26. 